DOSSIÊ TEMÁTICO: Vitalidade do sujeito e poder de formação: narrativas autobiográficas em diálogo

\title{
NARRATIVA (AUTO)BIOGRÁFICA E SUAS CONTRIBUIÇÕES: DA PRODUÇÃO DO CONHECIMENTO À FORMAÇÃO DOS SUJEITOS
}

\author{
(AUTO)BIOGRAPHICAL NARRATIVE AND ITS CONTRIBUTIONS: FROM THE \\ PRODUCTION OF KNOWLEDGE TO THE FORMATION OF SUBJECTS
}

\author{
LA NARRATIVA (AUTO)BIOGRÁFICA Y SUS CONTRIBUCIONES: DESDE LA \\ PRODUCCIÓN DE CONOCIMIENTOS HASTA LA FORMACIÓN DE SUJETOS
}

Camila Aloisio Alves

Faculdade de Medicina de Petrópolis - Brasil

\begin{abstract}
Resumo: O presente artigo tem por objetivo tecer algumas reflexões centradas na abordagem (auto)biográfica com vistas a caracterizar os processos inscritos na construção narrativa e seus efeitos sobre o narrador e sobre o pesquisador. $\mathrm{O}$ alcance deste objetivo será guiado pela narrativa de um profissional de saúde que compôs o grupo de participantes da pesquisa de pós-doutoramento da autora na França que, tomada como exemplo, permite apontar para cinco elementos de resposta à busca pela vitalidade do sujeito que a narrativa (auto)biográfica coloca em relevo: dar forma às experiências vividas através das palavras; levar o narrador a entrar em contato com novas facetas das situações vividas; estar a serviço da compreensão da construção do indivíduo que nasce do exame da sua trajetória de vida sem, contudo, perder de vista o cruzamento da mesma com a dimensão espaço-tempo social; basear-se na coconstrução do conhecimento; adentrar por meio das histórias de vida dos sujeitos na dimensão analítica e global da experiência. Conclui-se que a narração das experiências vividas é tanto ato organizador do vivido, quanto espaço de produção de novas percepções, compreensões e perspectivas. O compromisso em compreender o sujeito a partir desta abordagem está em assumir o compromisso ético de engajamento junto aos mesmos e as suas realidades de vida, dentro de um paradigma do singular plural, que tem na co-construção a condição de possibilidade de produzir conhecimentos situados e implicados com os modos de ser, estar e agir no mundo.
\end{abstract}

Palavras chave: Narrativa; Abordagem (auto)biográfica; Experiência.

Abstract: This article aims to weave some reflections centered on the (auto)biographical approach in order to characterize the processes inscribed in the narrative construction and their effects on the narrator and the researcher. The achievement of this objective will be guided by the narrative of a health professional who composed the group of participants of the author's post-doctoral research in France, which, taken as an example, allows pointing out five elements of response to the search for the vitality of the subject that the (auto)biographical narrative highlights: to give shape to the experiences lived through words; to bring the narrator into contact with new facets of lived situations; to be at the service 
of understanding the construction of the individual that is born from the examination of his life trajectory without, however, losing sight of its intersection with the space-time social dimension; to be based on the co-construction of knowledge; to enter through the life stories of the subjects into the analytical and global dimension of experience. It is concluded that the narration of lived experiences is both an organizing act of what is lived and a space for the production of new perceptions, understandings and perspectives. The commitment to understand the subject from this approach is to assume the ethical commitment of engagement with them and their realities of life, within a paradigm of the plural singular, which has in co-construction the condition of the possibility of producing knowledge situated and involved with the ways of being, being and acting in the world.

Keywords: Narrative; (auto)biographical approach; Experience

Resumen: Este artículo pretende tejer algunas reflexiones centradas en el enfoque (auto)biográfico con el fin de caracterizar los procesos inscritos en la construcción de la narración y sus efectos sobre el narrador y el investigador. El logro de este objetivo estará guiado por el relato de un profesional de la salud que formó parte del grupo de participantes en la investigación posdoctoral del autor en Francia, que, a modo de ejemplo, permite señalar cinco elementos de respuesta a la búsqueda de la vitalidad del sujeto que el relato (auto)biográfico pone de relieve: dar forma a las experiencias vividas a través de las palabras; poner al narrador en contacto con nuevas facetas de las situaciones vividas; estar al servicio de la comprensión de la construcción del individuo que nace del examen de su trayectoria vital sin perder de vista, sin embargo, su intersección con la dimensión social espacio-temporal; basarse en la coconstrucción del conocimiento; entrar a través de las historias de vida de los sujetos en la dimensión analítica y global de la experiencia. Se concluye que la narración de las experiencias vividas es a la vez un acto de organización de lo que se vive y un espacio para la producción de nuevas percepciones, comprensiones y perspectivas. El compromiso de entender el tema desde este enfoque es asumir el compromiso ético de comprometerse con ellos y sus realidades de vida, dentro de un paradigma del plural singular, que tiene en co-construcción la condición de la posibilidad de producir conocimiento situado e involucrado con las formas de ser, estar y actuar en el mundo.

Palabras clave: Narrativa; enfoque (auto)biográfico; Experiencia.

\section{Introdução}

O desafio deste dossiê está em caracterizar práticas narrativas, formalizar seus procedimentos e especificar os tipos de efeitos que produz sobre a dinâmica da formação de si. Buscando contribuir com o debate, o presente artigo tem por objetivo tecer algumas reflexões centradas na abordagem (auto)biográfica com vistas a caracterizar os processos inscritos na construção narrativa e seus efeitos sobre o narrador e sobre o pesquisador. $\mathrm{O}$ alcance deste objetivo será guiado pela narrativa de um profissional de saúde que compôs o grupo de participantes da pesquisa de pós-doutoramento da autora na França ${ }^{1}$ que, tomada como

\footnotetext{
${ }^{1} \mathrm{O}$ objetivo da referida pesquisa foi compreender como os profissionais que trabalham nos cuidados pediátricos intensivos, de reanimação e paliativos formam-se através das experiências vividas. O local de estudo foi um serviço de reanimação pediátrica e cuidados intensivos de um hospital de referência aos cuidados de crianças, situados na cidade de Paris/ França. Trata-se de um serviço composto por 32 leitos, que conta com 13 médicos, além de
} 
exemplo, permitirá ilustrar as reflexões que se pretende explorar no corpo deste artigo. Contudo, é importante que um agradecimento especial seja dedicado aos 17 profissionais que participaram da fase das entrevistas narrativas biográficas e aos mais de 100 profissionais que, direta e indiretamente, participaram da fase de observação participante da pesquisa em questão. Sem a abertura, a colaboração e a generosidade de toda a equipe, esta pesquisa não teria sido realizada.

Empreender uma pesquisa com base na abordagem (auto)biográfica exige do pesquisador atentar-se para vários elementos inscritos nas relações interpessoais e dialógicas, velando para que a sua postura e atitude favoreçam as trocas e partilhas que serão construídas no contexto da pesquisa. A escolha pela abordagem (auto)biográfica como base epistemológica, mas sobretudo metodológica, coloca o pesquisador diante do exercício precípuo de valores e princípios como a empatia (JANNER RAIMONDI, 2017), a alteridade, da escuta ativa (ROGERS, 1967) e de uma atitude compreensiva (Porter, 1950) que favorecem o respeito e o estabelecimento de elos de confiança, princípios fundamentais para a construção narrativa dos participantes. Contar uma história de vida é um exercício de partilha que só é possível se o respeito, a confiança e a escuta ativa pautam as trocas entre pesquisador e os participantes. Ademais, o participante da pesquisa sendo o detentor da história, dos saberes adquiridos e narrador da própria experiência é parte fundamental na construção do conhecimento (ALVES e DIZERBO, 2017; 2020).

A apreciação de tais aspectos e a reflexão teórica sobre a temática de estudo realizada previamente ao trabalho de campo são correntemente preocupações dos pesquisadores e por isso não cabe, no escopo deste artigo, alongar-se nestes aspectos. Entretanto, os processos inscritos e que são desencadeados pelo ato de ser convidado a narrar a sua história, de trazer à linguagem o vivido e de expressá-lo dentro de uma coerência interna ao indivíduo (BRETON, 2020), serão alvo das reflexões que se seguem, buscando colocá-los em relevo de modo a captar a contribuição específica do trabalho narrativo (auto)biográfico.

Para tanto, carece caracterizar a investigação narrativa e especificar seus usos. Enquanto processo sistemático para produção de conhecimentos, a investigação narrativa é uma via de acesso e de produção do conhecimento que busca levar o pesquisador a compreender o vivido

psicólogos, terapeuta ocupacional, assistente social, educadora hospitalar, enfermeiros, técnicos de enfermagem e secretárias, que juntos compõem a equipe do serviço. A pesquisa desenvolveu-se segundo a abordagem (auto)biográfica (DELORY-MOMBERGER, 2012; 2014; JOSSO, 2004; 2007). e foi realizada entre os meses de Junho/ 2018 à Setembro/2019 e contou com entrevistas narrativas biográficas e observação participantes como método de exploração do campo (Alves, 2020). 
através da expressão em palavras em "primeira pessoa" (Breton, 2020), ou seja, através de uma fala encarnada no indivíduo, que tem como matéria-prima o vivido, o experienciado e o aprendido pelo mesmo. Tal como aponta o autor, "somente a pessoa que vive a experiência de um fenômeno encontra-se capaz de dizer, a partir do seu ponto de vista e com as suas próprias palavras, sobre o que ela viveu, os efeitos que ela experienciou e os impactos experienciais e biográficos sofridos” (BRETON, 2020, p. 13).

Assim, para narrar, cabe ao indivíduo fazer um movimento de retorno sobre si mesmo, selecionando, organizando temporalmente as experiências vividas e dando forma a esse exercício através das palavras. Ainda que esse movimento seja tomado pelas investigações como espaço de produção e suporte de reflexão, o fato é que a capacidade de narrar é inerente e imanente ao humano. É através dessa capacidade que operamos uma configuração temporal (RICEUR, 1983), que ordenamos os fatos vividos (PINEAU e LEGRAND, 1993), que os reconstruímos subjetivamente e que os apreendemos objetivamente através de esquemas, padrões e figuras de linguagem (DELORY-MOMBERGER, 2014).

A investigação narrativa convida, portanto, o indivíduo a entrar em um processo de construção de uma identidade através da qual uma ordenação e uma lógica serão conferidas aos eventos vividos (RICCEUR, 1985; JANNER-RAIMONDI, 2019). À luz dos estudos de Michel (2003) sobre Ricœur, a identidade narrativa vem a ser o terceiro componente ${ }^{2}$ da identidade pessoal e que pode ser definida como a capacidade da pessoa em expressar através das palavras e de maneira concordante os eventos que caracterizam a sua existência.

E se toda existência se dá em um espaço-tempo, a narrativa é entendida também como um lugar de cruzamento entre os sentidos e a objetividade dados pelo indivíduo às experiências vividas na sua relação com o mundo ao redor. O sujeito que narra traz consigo a cultura na qual está inserido, a dimensão social do vivido. A narrativa torna visível portanto o atravessamento entre as dimensões pessoais e sociais do sujeito e constitui-se como um espaço de produção de textos nos quais diferentes mundos da vida do sujeito podem ser vistos e nos quais a experiência do mesmo é corporizada (RICCEUR, 1965).

Posto isto, é importante distinguir os "regimes narrativos" a fim de refletir sobre os processos inscritos na construção narrativa e seus efeitos. Partindo dos estudos de Breton (2020), temos o regime biográfico e o regime da micro-fenomenologia. Ainda que o cruzamento

\footnotetext{
${ }^{2}$ A título de informação, o primeiro componente para Ricœur refere-se à identidade-idem que remete à noção psicossociológica de caráter, ou seja, o conjunto de disposições adquiridas pelas quais se reconhece uma pessoa. O segundo componente, a identidade-ipse, é definido como sendo a manutenção voluntária de si mesmo diante dos outros (MICHEL, 2003).
} 
entre ambos seja profícuo e estimulante ${ }^{3}$, caberá a este artigo deter-se sobre o primeiro que, em termos de temporalidade, coloca em perspectiva a trajetória de vida e a sua dimensão longitudinal. Ou seja, o vivido ao longo do tempo passa a ser objeto de apreciação e elaboração para ser expresso em palavras que deverão cumprir com a tarefa, por vezes árdua, de comprimir os detalhes (BRETON, 2020). Todavia, tal como aponta o autor, ainda que o acesso aos detalhes das experiências vividas esteja em segundo plano, o produto da experiência, isto é, aquilo que foi aprendido e que constitui saberes experienciais ganha corpo e forma através da narrativa biográfica. Tem-se, portanto, não só uma especificidade deste regime narrativo, mas também sua potencialidade, que merece ser abordada e explorada no próximo tópico para que, na sequência, seja possível aprofundar as reflexões deste artigo de forma dialogada com o exemplo escolhido.

\section{Abordagem (auto)biográfica: breve retorno a aspectos epistemológicos}

Começar esta seção é, sobretudo, indagar-se sobre o que torna a capacidade inerente e imanente do humano de narrar, um meio e um terreno de estudo, de reflexão e de produção do conhecimento? Que processos são possíveis de serem apreendidos através da narração (auto)biográfica? O que torna este regime narrativo um meio de acesso à dimensão da formação (auto)biográfica?

Responder essas perguntas exige fazer um retorno aos aspectos epistemológicos trabalhados por alguns autores do campo da pesquisa (auto)biográfica. Sem a pretensão de ser exaustivo e detalhado, este retorno visa apontar para contribuições que permitem compreender a formação dos indivíduos por meio das experiências vividas e como as mesmas engendram formas de ser e estar no mundo.

Segundo Josso (2007), a narração das histórias de vida permite desencadear um trabalho transformador do indivíduo, uma vez que ao dar forma, através das palavras, à formação que se inscreve no curso de uma trajetória de vida, pode-se acessar uma multiplicidade de sentidos e modos de ser e agir no plano individual e coletivo. $\mathrm{O}$ ato do narrador debruçar-se sobre o conjunto de elementos que compõem e dão sentido a sua história, o uso da sua capacidade de

\footnotetext{
${ }^{3}$ Para maiores informações acerca das contribuições do cruzamento entre os regimes narrativos no campo da saúde, especialmente no que tange a abordagem da Educação Terapêutica de Pacientes, sugere-se a consulta ao site https://www.creacast.com/channel/viastoria-etp-200924/ onde o leitor pode conhecer um pouco sobre o projeto de pesquisa e formação "Croiser les expériences: vers une transformation de l'action de soin dans la maladie chronique" desenvolvido pelo Groupe Hospitalière de la Région de Mulhouse et sud Alsace e coordenado pela Dra. Geneviève Beck-Witrth.
} 
ordená-las no tempo e a oportunidade de tomar consciência sobre o trabalho empreendido para construir-se por meio do vivido é uma forma de reatulização da própria história, podendo dela tirar novos ensinamentos e construir novos olhares. Tal como nos aponta Passeggi (2014) e Passeggi, Nascimento e Oliviera (2016), é através da reflexividade autobiográfica que o humano se coloca disponível para refletir sobre si mesmo e sobre as experiências vividas. Já para o pesquisador, a narração biográfica permite apreender os processos que participam da construção do indivíduo no espaço social, percepcionando as maneiras pelas quais o mesmo dá forma as suas experiências. Acessa-se o que Delory-Momberger (2014) chama de processo de biografização, um conjunto de operações pelas quais os indivíduos buscam dar uma forma própria ao que foi vivido, experimentado, conhecido.

O trabalho, de formação ou investigação, de base (auto)biográfica permite, portanto, "evidenciar e questionar as heranças, a continuidade e a ruptura, os projetos de vida, os múltiplos recursos ligados às aquisições de experiência" (JOSSO, 2007, p. 414). Sem dissociar o indivíduo do social e nem estabelecendo hierarquias ou procurando forças determinantes, o trabalho que se pode empreender por meio da abordagem (auto)biográfica confere aos envolvidos (narrador e pesquisador ou formador) o acesso aos fios que permitem relacionar as transformações sociais e culturais ao universo de vida dos indivíduos. Trata-se de priorizar um trabalho de compreensão voltado para a formação de uma "subjetividade singular e plural" (JOSSO, 2007). Nesta mesma esteira, Delory-Momberger aponta: "O homem está no mundo. Ele o transforma e se transforma na medida que as mudanças que ele provoca geram efeitos em si mesmo. A relação entre o homem e o mundo é de formação mútua” (2014, p. 59). Segundo Souza, (2007, p. 65-66):

Ao longo de seu percurso pessoal, consciente de suas idiossincrasias, o indivíduo constrói sua identidade pessoal mobilizando referentes que estão no coletivo. Mas, ao manipular esses referentes de forma pessoal e única, constrói subjetividades, também únicas. Nesse sentido, a abordagem biográficonarrativa pode auxiliar na compreensão do singular/universal das histórias, memórias institucionais e formadoras dos sujeitos em seus contextos, pois revelam práticas individuais que estão inscritas na densidade da História.

Sendo assim, a construção narrativa sob a perspectiva (auto)biográfica é também um espaço de produção onde as dimensões individuais e sociais que compõem a vida dos indivíduos cruzam-se, tornando visível o enredo elaborado pelo indivíduo e que dá corpo a sua existência. A narrativa torna visível o que o termo Bildung busca conceituar: os processos de formação por meio das experiências vividas e de transformação do ser ao longo do tempo em uma dinâmica de ampliação progressiva (DELORY-MOMBERGER, 2011a; 2011b). Diante dos elementos 
que a narrativa biográfica torna visível, emerge o convite para empreender um exercício hermenêutico de compreensão do conjunto complexo dos componentes que engendram essa transformação e que permite, com isso, entender a construção identitária do ser no espaçotempo social.

Para tanto, captar as "situações educativas" (Josso, 2007) que as experiências vividas engendram no espaço e no tempo e que são evocadas pelo narrador no curso da narrativa vem a ser um caminho para o exercício hermenêutico em questão. Trata-se de apreender que no tecido das vivências que constituem o cotidiano dos indivíduos, existem experiências que carregam o potencial de aprendizagem se a elas são dirigidas atenção e reflexão (JOSSO, 2004). Como aponta Delory-Momberger (2014), as experiências vividas constituem possibilidades de aprendizagem na vida (do alemão Erlebnis), mas é o processo de elaboração e apropriação das mesmas por meio de operações mentais, verbais, comportamentais que permite transformá-las em aprendizado (do alemão Erfahrung).

Pode-se entender, portanto, que a capacidade de ordenar as experiências no tempo, de produzir um movimento de reflexividade sobre as mesmas e de tirar aprendizados para a vida que configuram formas de agir dota o indivíduo de uma capacidade de integrar a seu arsenal biográfico novas experiências àquelas que já forma feitas. Para esse movimento Alheit e Dausien (2005) cunharam o termo biographicitélbiograficidade, que na leitura crítica de Stauber (2018), refere-se ao modo pelo qual uma realidade social sempre nova é apropriada um modo que está sempre aberto para transformação através de processos empreendidos pelo indivíduo no curso da sua trajetória de vida, sejam eles de negociação, de explicação, de correspondência ou de ressignificação. Ou seja, face às experiências vividas, o indivíduo não está sempre assumindo a mesma posição e postura ao viver e integrar novas experiências. Nem todas as experiências têm a mesma capacidade de integração, seja porque reproduzem experiências prévias e, por isso, pode-se reconhecê-las e integrá-las mais facilmente, seja porque o seu ineditismo exige um trabalho de interpretação - um trabalho biográfico - mais custoso para que o indivíduo seja capaz de ajustá-las às experiências passadas.

Nesse sentido, o estudo das narrativas (auto)biográficas é aquele que se detém em compreender a forma como os indivíduos experimentam o mundo nos níveis da linguagem, dos sentimentos e dos pensamentos (CLANDININ; LESSARD; CAINE, 2012). Para estes autores, a identidade é uma construção fruto de fenômenos relacionais que se constituem no contato do indivíduo com situações, pessoas e com lugares que desencadeiam um trabalho permanente de definição e redefinição do ser e das suas formas de estar e agir no mundo. 
Para explorar as perspectivas teóricas expostas nesta seção e buscando responder aos desafios postos pelo dossiê, a próxima seção buscará trabalhar a dimensão da vitalidade do sujeito que as narrativas (auto)biográficas têm como potência de atingir e trabalhar.

\section{Contribuições específicas e singulares do trabalho narrativo (auto)biográfico}

O desenvolvimento desta seção foi guiado pela construção da narrativa de Olivier, que tomada como exemplo, será usada como forma de conduzir as reflexões que se pretende explorar. Composta por quatro subseções, busca-se explorar as contribuições específicas e singulares do trabalho narrativo (auto)biográfico nas diferentes fases da pesquisa: da construção narrativa à partilha dos resultados.

\section{- A construção da narrativa}

Oliver (pseudônimo) é um pediatra intensivista que trabalha no serviço de reanimação pediátrica do hospital de estudo da pesquisa há quase 20 anos. Sua narrativa, desencadeada pelo convite - "Gostaria que me contasse como se construiu sua trajetória de formação e de trabalho na medicina e no campo dos cuidados intensivos e paliativos?" - teve duração de 1h16'20”. Ao longo desse tempo, Olivier retraçou sua trajetória desde a faculdade, os motivos que o levaram a escolher a medicina, suas opções e tendências de escolhas por certas especialidades, sua residência em pediatria, seu contato com os cuidados intensivos e com as urgências, seu período no exército, os estágios extras que realizou até chegar no hospital de estudo e encontrar um posto de trabalho que foi evoluindo no tempo, cada vez com mais responsabilidades e desafios. A cartografia abaixo permite ter uma visão geral desta trajetória, organizada segundo as grandes etapas evocadas por Olivier, os anos marcantes e concluindo com a data de realização da entrevista.

\section{Figura 1 - cartografia cronológica da trajetória de Olivier}

$1996 \quad$ Entre os anos de 1998 e 2000

Fonte: a autora. 
Naquela 1h16'20" Olivier contou o decorrer de quase 30 anos de uma trajetória de vida, o que permite retomar o exposto na introdução deste artigo acerca da primeira característica deste tipo de regime narrativo: captar a dimensão longitudinal do vivido (BRETON, 2020).

A captação desta dimensão tem como primeiro efeito uma compressão temporal que faz caber em uma entrevista o tempo de décadas de uma vida. Ainda que Olivier tenha sido informado que poderia usar todo tempo que quisesse para construir sua narrativa, contar sobre o que viveu é sempre um retorno a uma "experiência de referência" que, segundo o esquema desenvolvido por Breton (2020), mantem-se situada na história do indivíduo de forma não evolutiva quanto a sua perspectiva temporal. Entretanto, o que se expõe na narrativa é a "situação narrativa" (BRETON, 2020), que se constrói no ato de debruçar-se sobre si mesmo e de construir uma fala incarnada no momento presente, fazendo com que o narrador olhe para o vivido com a capacidade de elaborá-lo sempre de forma atualizada. Tem-se, com isso, um primeiro elemento de resposta à busca pela vitalidade do sujeito que a narrativa (auto)biográfica coloca em relevo. Ou seja, ao assumir e pôr em ação uma identidade narrativa, o sujeito entra em contato com a sua história para lhe dar forma e visibilidade através das palavras e organizá-la no tempo.

Compreendida essa dinâmica, a possibilidade de explorar a narrativa de forma dialógica, empática e através de uma atitude compreensiva, confere ao pesquisador a capacidade de acompanhar o narrador na exploração de certos aspectos para que as dimensões da experiência sejam revisitadas e colocadas em relevo. Um conceito caro para que esse trabalho de exploração e enriquecimento da narrativa seja empreendido diz respeito a noção de trajetória enquanto "lugar de tensão entre a padronização social do curso da existência e a capacidade do indivíduo de agir sobre sua vida e sobre as determinações que pesam sobre a mesma" (DELORYMOMBERGER, 2009, p. 20). Ainda que seja possível construir uma cartografia temporal da trajetória de Olivier, no interior da mesma estão inscritas suas experiências que o convidaram a viver momentos de (re)descobertas, hesitações, dúvidas, certezas... São estas linhas “experimentais” que dão um esboço, uma forma, uma expressão à identidade do indivíduo.

Portanto, ao avançar no trabalho de construção narrativa, o diálogo entre pesquisador e narrador cria um espaço de troca embasado pelos valores e princípios explicitados na introdução do presente artigo. Através dos mesmos pode-se explorar e preencher a narrativa de vivências, de eventos marcantes, de momentos de bifurcação e de viradas que engendram decisões, acelerações, desacelerações, continuidades, descontinuidades, conexões e tensões entre várias temporalidades da existência e que são tecidas entre as diferentes dimensões da vida. A cartografia da trajetória de vida ganha, com isso, ainda mais corpo, tal como é possível observar 
através da figura abaixo, que foi construída com vistas a dar visibilidade aos principais temas e motivos que foram evocados por Olivier em cada uma das grandes etapas de sua trajetória.

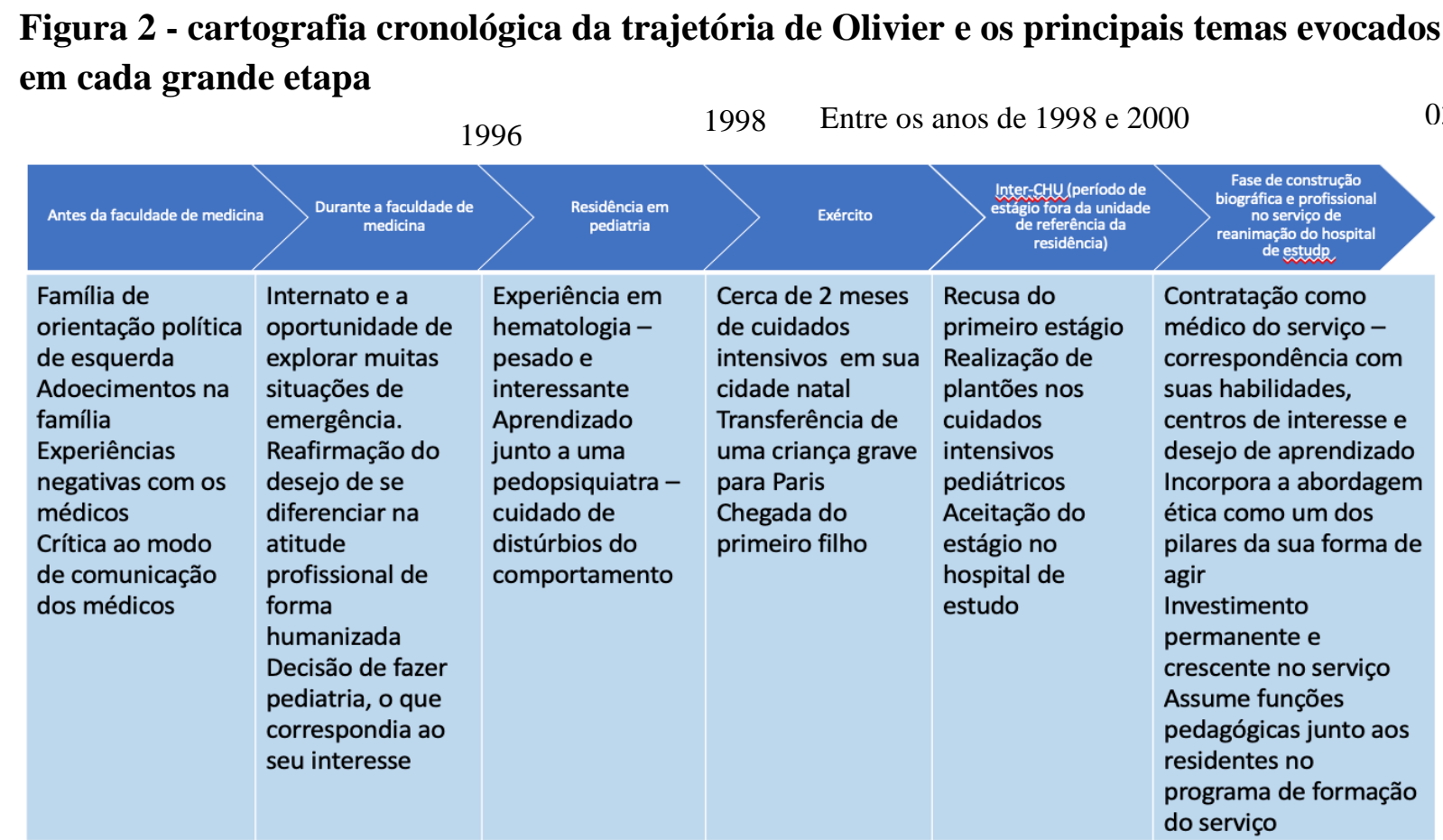

Fonte: a autora.

Assim, as grandes etapas colocadas em relevo por Olivier, segundo a sua lógica interna de organizar o que foi vivido, foram no curso da narrativa preenchendo-se de um conjunto de experiências que são, para o próprio narrador, os elementos que deram forma a sua construção como indivíduo. Pode-se, assim, apontar para o segundo elemento de resposta que está em jogo ao buscar localizar a força que a narrativa (auto)biográfica engendra no sujeito: o ato de revisitar sua história de vida, colocá-la em palavras, selecionar os temas e motivos importantes a serem evocados na partilha com o pesquisador, leva o narrador a entrar em contanto com novas facetas das situações vividas. A potência não se esgota apenas em acessá-las, mas expande-se ao fazê-la a partir do próprio olhar do momento presente, do momento de construção narrativa, o que confere ao narrador a possibilidade de (re)descobrir recursos, forças pessoais e (re)atualizar o vivido. É nessa potência que reside o processo de antropoformação (Paul, 2009), através do qual compreende-se que o sujeito é capaz de promover as pontes entre os conhecimentos, saberes e vivências. É da formação do indivíduo no contexto da interação com a sociedade que emerge a capacidade de promover novas conexões, criando novas saídas e respostas para as situações vividas 


\section{- A interpretação da narrativa}

A possibilidade de continuar explorando as contribuições específicas e singulares do trabalho narrativo (auto)biográfico reside no trabalho de interpretação da narrativa, por meio do qual os principais conceitos expostos na seção anterior deste artigo orientam o pesquisador a buscar chaves de interpretação que vão servir de elos entre o texto e o produto que se pode extrair em termos de aprendizado.

Se através da abordagem (auto)biográfica busca-se compreender a construção do indivíduo por meio das experiências vividas, bem como os saberes que delas emergem, é preciso apreender na narrativa o que Josso (2007) chama de situações educativas, ou seja, situações que se constroem situadas no tempo e no espaço e que levam o indivíduo a certas tomadas de consciência, decisões, posicionamentos, enfim, a agir sobre si. Trata-se de apreender a dinâmica entre Erlebnis e Erfahrung (DELORY-MOMBERGER, 2014).

Captar essas situações educativas exige, por um lado, assumir a experiência como aquilo que se constitui ao longo do tempo, através da confrontação cotidiana do indivíduo com a realidade, sendo tanto individual, quanto coletiva (JOBERT, 1991). Ou como aponta Barbier (2013), a experiência pode ser entendida como "as transformações imediatas que ocorrem em um sujeito durante o curso de uma atividade" (p. 15). Considerando que a narrativa (auto)biográfica capta a experiência ao longo do tempo, no curso de uma trajetória de vida e que se constitui a partir do tecido vivencial (JOSSO, 2004) que envolve o cotidiano do narrador, é esperado que o mesmo seja capaz de verbalizar o que pôde adquirir como aprendizado a partir das experiências vividas.

No caso da narrativa de Olivier, um conjunto de aprendizados são por ele mesmo elencados e que se conformaram a partir do vivido, tais como a adoção da abordagem ética sustentada pelo serviço e que orienta o trabalho multiprofissional com vistas a melhor conduzir os projetos terapêuticos, sejam eles de reanimação, sejam eles de cuidados paliativos. No mais, foram elencados os aprendizados relacionais e comunicacionais aprendidos junto aos colegas, às crianças e suas famílias; aprendizados pedagógicos, incorporados mais recentemente em sua trajetória profissional devido ao seu engajamento na formação dos residentes. Pode-se entender que esses aprendizados, selecionados e listados por Olivier constituem o que Cavaco (2009) aponta em seus estudos como sendo a experiência enquanto resultado, um produto do vivido, sedimentado e visível através do que foi adquirido e que serve de ferramenta para o agir do indivíduo. 
Todavia, a narrativa de Olivier é atravessada por um conjunto de situações educativas, de onde as experiências podem ser olhadas enquanto processos (Cavaco, 2009), levando o trabalho interpretativo da narrativa a um patamar de captação dos elementos que constituem tais processos e fazem dele emergir aprendizados. Para empreender esta tarefa, é preciso adotar uma postura de abertura para conjugar diferentes chaves de interpretação seguindo a perspectiva que Ricœur (1965) chama de "via longa", na qual cabe ao pesquisador esforçar-se para usar os recursos necessários que lhe permitam adentrar no trabalho subjetivo empreendido pelo indivíduo no curso da sua narrativa.

É neste ponto que o trabalho de interpretação adentra na dimensão processual dos saberes experienciais e dá um salto para além da identificação dos aprendizados adquiridos. É através deste salto que se pode evocar o terceiro elemento de resposta à contribuição específica do trabalho narrativo: estar a serviço da compreensão acerca da construção do indivíduo que nasce do exame da sua trajetória de vida sem, contudo, perder de vista o cruzamento da mesma com a dimensão espaço-tempo social. Nas palavras de Josso (2007, p. 431), trata-se da "fecundidade do paradigma do singular plural, associado ao paradigma do experiencial, pelo viés da abordagem biográfica".

Retomando a interpretação da narrativa de Olivier, o trabalho interpretativo encontrou nas contribuições de Pineau e Marie-Michèle (2012) o conceito de transação que se refere à ação que produz uma relação entre dois elementos descritos na narrativa. Esta ação vem a ser, por um lado, um processo de elaboração do indivíduo frente à experiência vivida, e por outro lado, gera produtos que podem ser entendidos como aprendizados que emergem de situações que passam a ser educativas. Retomando a narrativa de Olivier, foi possível identificar muitos momentos de transação produzidos por situações educativas ora formais, ora informais. $\mathrm{O}$ encontro de Olivier com tais situações, a confrontação com dificuldades e desafios que exigiram novos posicionamentos e respostas, assim como certas experiências que contribuíram para a definição de certos rumos para a sua carreira compõem o conjunto de saberes e conhecimentos que conformam sua trajetória e dão forma ao seu modo de ser, estar e agir. Para facilitar a compreensão, o esquema abaixo foi elaborado com vistas a ilustrar alguns dos muitos dos momentos de transação, incluindo trechos da narrativa: 
Figura 3 - Esquemas exemplificadores de transações identificadas na narrativa de Olivier:

\begin{tabular}{|c|c|c|}
\hline \multicolumn{2}{|c|}{ Situações educativas vividas e narradas } & Resultado da transação \\
\hline $\begin{array}{l}\text { Residência em } \\
\text { pediatria }\end{array}$ & $\begin{array}{l}\text { Transferência para } \\
\text { Paris de uma criança } \\
\text { com risco de vida }\end{array}$ & $\begin{array}{l}\text { Tomada de consciência do quanto a } \\
\text { natureza do trabalho de urgência lhe } \\
\text { agradava: "Experiência genial" }\end{array}$ \\
\hline $\begin{array}{l}\text { Contratação } \\
\text { pelo serviço de } \\
\text { reanimação }\end{array}$ & $\begin{array}{l}\text { Encontro com os } \\
\text { colegas, com os } \\
\text { pacientes e com o } \\
\text { ambiente de trabalho }\end{array}$ & $\begin{array}{l}\text { Confirmação que a escolha feita fora a } \\
\text { melhor: "A lembrança é de um trabalho } \\
\text { realizado em um universo fechado, } \\
\text { extremamente intenso, com pessoas que } \\
\text { resnondiam an meu deseio de anrender }\end{array}$ \\
\hline $\begin{array}{l}\text { Confrontação } \\
\text { cotidiana com } \\
\text { situações de fim } \\
\text { de vida }\end{array}$ & $\begin{array}{c}\text { Engajamento na } \\
\text { abordagem ética } \\
\text { adotada pelo serviço }\end{array}$ & $\begin{array}{l}\text { Ressignificação do trabalho em reanimação } \\
\text { pediátrica: “É o princípio de aceitar em ser } \\
\text { o portador desta violência [reanimar um } \\
\text { corpo em risco de vida] e aceitamos } \\
\text { porque sabemos que podemos metabolizá- }\end{array}$ \\
\hline $\begin{array}{l}\text { Cuidado de uma } \\
\text { criança cujos pais } \\
\text { viviam uma } \\
\text { situação complexa } \\
\text { de precariedade } \\
\text { social e conflito }\end{array}$ & $\begin{array}{c}\text { Trabalho em parceria } \\
\text { com as psicólogas do } \\
\text { serviço }\end{array}$ & $\begin{array}{l}\text { Compreensão de aspectos emocionais e } \\
\text { psíquicos que atravessam o cuidado e } \\
\text { valorização do trabalho interdisciplinar: } \\
\text { "Você sente que tem desafios que você não } \\
\text { consegue resolver e ao colocar tudo isso } \\
\text { em uma história global, pude aprender a } \\
\text { diminuir a tensão que atravessava o caso e } \\
\text { melhor usar os recursos de comunicação }\end{array}$ \\
\hline
\end{tabular}

Pode-se observar que os aprendizados evocados enquanto resultado, listados por Olivier em sua narrativa, e os aprendizados captados enquanto processo criam zonas de interseção que favorecem a compreensão da sua construção. O uso de chaves de interpretação que ajudam a captar o modo como os aprendizados se dão permite que o trabalho de pesquisa vá além de uma lista descritiva de saberes, pois coloca em evidência tanto o poder de formação contido no sujeito e nas situações vividas, quanto as formas de constituição dos aprendizados no espaço-tempo social e no seio das relações sociais. Parafraseando Dominicé (2007), extrapola-se as fronteiras entre saberes formais e informais, mostrando o enredo de relações que se estabelece entre eles e legitimando os aprendizados construídos ao longo da trajetória de vida.

É importante ressaltar que o uso do conceito de transação não pressupõe tomá-lo como única chave de interpretação capaz de fazer o pesquisador adentrar nos processos de formação do sujeito pelas experiências vividas e de constituição dos saberes experienciais. A sua escolha deveu-se a sua pertinência com o tema de estudo e os processos que aí se inscreveram. No 
contexto da pesquisa em tela, outros conceitos compuseram as chaves de interpretação e forneceram ainda mais elementos para compreender as trajetórias de formação dos profissionais entrevistados ${ }^{4}$. Dito isto, cabe passar para o último ponto que compõe essa seção a fim de explorar o quarto elemento de resposta ao desafio posto neste dossiê.

\section{- Ressonâncias narrativas e interpretativas}

Para abordar o quarto elemento de resposta, cabe fazer um retorno ao compromisso com a partilha e com a co-construção do conhecimento. Por isso, foram previstos diferentes momentos de restituição do trabalho de pesquisa. O primeiro deles foi o envio da entrevista transcrita para que o narrador pudesse ler e porventura completar ou corrigir alguma passagem que não tenha ficado clara. O segundo aconteceu logo após a conclusão da etapa da interpretação, quando cada participante recebeu um documento composto por: uma explicação de como o trabalho interpretativo foi realizado; uma cartografia completa da trajetória de vida narrada, incluindo as grandes etapas da narrativa, os eventos marcantes, os momentos de bifurcação e de virada; um texto interpretativo onde as chaves de interpretação foram colocadas em diálogo com na narrativa, fazendo uso de trechos da mesma para exemplificar e ilustrar as reflexões do pesquisador. $\mathrm{O}$ envio foi feito individualmente e cada participante teve a chance de conversar com o pesquisador sobre suas impressões e expor seus comentários sobre o trabalho realizado.

Especificamente, Olivier viveu diferentes momentos através dos quais as ressonâncias do trabalho puderam ser sentidas. Durante a sua entrevista, no avançar das reflexões que se sucederam, Olivier pôde colocar em perspectiva as experiências vividas e perguntado sobre como via toda a sua trajetória a partir do olhar do momento presente, ele responde: “... Muito emocionante tentar me reaproximar [das experiências vividas] ... o que é bizarro, não esperava tudo isso... enfim,... uma sensação, uma convicção de ter feito alguma coisa boa. Isso sim... pelos outros e por mim, a sensação de ter feito uma boa escolha" (03/07/18). Nesse sentido, a reflexividade desencadeada pelo ato de contar a sua história de vida produz um distanciamento da situação tal como ele foi vivida. Retomando Breton (2020), trata-se da "situação narrativa", que por levar o indivíduo a se posicionar através da sua identidade narrativa abre espaços de reflexão no próprio indivíduo que não podem ser vividos durante a experiência em ato. Indo ao

\footnotetext{
${ }^{4}$ Para maiores esclarecimentos a esse respeito, sugere-se a leitura de Alves, C. A. L'approche biographique et la temporalité des soins palliatifs aux enfants malades chroniques: des apprentissages qui se tissent entre la vie et la mort. Disponível em: http://www.periodicoseletronicos.ufma.br/index.php/cadernosdepesquisa e de Alves, C. A. O uso de narrativas biográficas em investigação: quais valores, posturas e métodos adotar? Aprovado pela Revista Portuguesa de Educação com publicação prevista para 2021.
} 
encontro de Josso (2007, p. 419), "a história de vida é, assim, uma mediação do conhecimento de si em sua existencialidade, que oferece à reflexão de seu autor oportunidades de tomada de consciência sobre diferentes registros de expressão e de representações de si, assim como sobre as dinâmicas que orientam sua formação".

Já em relação à restituição da interpretação de Olivier, foi possível observar uma outra ordem de ressonância produzida não só pelo olhar em perspectiva para a própria história de vida, mas também para a interpretação proposta pelo pesquisador: "Eu nunca tinha me visto sob essa perspectiva... interessante esse trabalho... faz todo sentido”(14/10/19).

Novos elementos de reflexão somam-se aqueles já levantados no curso da narrativa e ainda que esse momento de restituição do trabalho interpretativo seja delicado e exija um cuidado e atenção com relação a forma como ele se dará, ele é potente na sua dimensão heterobiográfica. Ou seja, na capacidade de trazer para a narrativa (auto)biográfica um olhar externo que se soma ao olhar do narrador, podendo dele surgir novas reflexões e perspectivas. Parafraseando Josso (2007) o momento coletivo de partilha de uma história de vida permite ao narrador ampliar o olhar sobre a própria história e refletir sobre a possibilidade de refletir sobre novos recursos, estratégias e possibilidades em sua vida.

Nesse sentido, podemos apontar para o quarto elemento de resposta quanto as contribuições do trabalho narrativo (auto)biográfico: basear-se na co-construção do conhecimento, o que restitui e faz circular o poder de formação inscrito na trajetória de vida dos indivíduos, valorizando suas forças e capacidades de se transformarem e de se reconstruírem em função das experiências vividas. Em última instância essa restituição é potente em sua capacidade de emancipar os sujeitos pelo que proporciona em termos de tomada de consciência.

\section{- Do singular ao plural}

Reiterando a compreensão de que a abordagem (auto)biográfica participa do "paradigma do singular plural” (JOSSO, 2007), suas contribuições não se esgotam no ato de interpretar as narrativas e dela extrair uma compreensão sobre a construção dos indivíduos por meio das experiências vividas. Participar e situar-se nesse paradigma, dando vida a uma lógica de produção de conhecimento que assume a singularidade do sujeito é tanto um compromisso ético de dar espaço e voz ao sujeito, quando uma orientação metodológica de como conduzir o trabalho de investigação e a produção do conhecimento. 
Entretanto, o trabalho narrativo (auto)biográfico não pode prescindir da dimensão "plural" inscrita na narrativa, seja enquanto dimensão da vida do indivíduo, seja enquanto espaço de produção, reprodução, construção e reconstrução do mesmo. Sobre esse aspecto, o terceiro elemento de resposta exposto neste artigo, cumpre a função de salientar. O que se pretende nesta última subseção é apontar para o compromisso de levar o trabalho de investigação (auto)biográfica a uma dimensão analítica onde a interpretação da narrativa de cada indivíduo serve de alavanca para um exercício de busca pela transversalidade do vivido. Ou seja, a narrativa de cada participante vem a ser o meio privilegiado que conduz o pesquisador a olhar o conjunto de experiências e de formações experienciais e deles encontrar pontos de interseção e de singularidade. É neste nível - analítico - que a investigação narrativa de base (auto)biográfica completa seu tour pelo paradigma no qual se situa. Ao cumprir com esse compromisso, reconhece-se o indivíduo, as experiências vividas, os processos formativos formais e informais, os saberes construídos no curso da trajetória, integrando-os a dimensão social da qual ele faz parte faz parte, a qual ele influencia e na qual ele se transforma.

Com base em seus estudos da obra de Paul Ricœur, Henriques (2014) salienta que através do discurso pode-se apreender e cruzar tanto os sinais e símbolos da linguagem, quanto a relação com o mundo estabelecida pelo indivíduo. Seguindo essa orientação, o trabalho interpretativo realizado sobre a narrativa de Olivier também foi realizado com os outros 16 profissionais que participaram da pesquisa e o olhar transversal para o conjunto de narrativas e suas interpretações permitiu encontrar pontos de interseção e captar os significados inscritos no processo de formar-se um profissional de saúde no serviço de reanimação pediátrica em um hospital de referência em Paris/França. O trabalho de investigação alcança, portanto, a dimensão coletiva do vivido, buscando compreender os fenômenos vividos de forma global e que participam da forma como o coletivo constrói e reatualiza suas ações de cuidado. Chegase, assim, ao quinto elemento de resposta: exercer a alteridade, tomando em um plano horizontal de produção do conhecimento, os sujeitos, suas histórias e seus processos formativos experienciais, adentrando por meio deles na dimensão social da experiência, valorizá-la e entendê-la através de um exercício dialógico entre as transformações sociais e culturais e o universo de vida dos indivíduos que dão corpo e forma a subjetividades singulares e plurais (JOSSO, 2007).

\section{Conclusão}

Partindo de uma trajetória de estudos e de pesquisa da autora, buscou-se tecer os elos entre conceitos e a operacionalização da investigação com vistas a dar visibilidade aos 
processos inscritos na construção das narrativas (auto)biográficas e seus efeitos tanto sobre o narrador, quanto sobre o pesquisador. Foi possível explicitar cinco elementos de resposta, que apesar de terem sido apresentados de forma separada, tecem no curso da investigação elos entre as etapas de trabalho e produzem reverberações tanto no pesquisador, quanto nos participantes. Estas reverberações favorecem a compreensão dos objetivos da pesquisa, valorizam o papel e o lugar dos sujeitos enquanto portadores e construtores do conhecimento e, por conseguinte, repercutem no grau de engajamento na sua co-construção no contexto da investigação.

Cabe ressaltar que os cinco elementos de resposta expostos no curso do presente artigo não pretendem esgotar todas as contribuições que a investigação narrativa (auto)biográfica traz para a produção do conhecimento. A escolha do foco do artigo centrado nas narrativas (auto)biográficas não permitiu, por exemplo, refletir sobre as especificidades do regime narrativo de explicitação, assim como explorar o seu cruzamento com a abordagem (auto)biográfica.

Embora as possibilidades de exploração deste regime narrativo sejam vastas, podemos concluir que a narração das experiências vividas é tanto ato organizador do vivido, quanto espaço de produção de novas percepções, compreensões e perspectivas. O compromisso em compreender o sujeito a partir desta abordagem está em assumir o compromisso ético de engajamento junto aos mesmos e as suas realidades de vida, dentro de um paradigma do singular plural, que tem na co-construção a condição de possibilidade de produzir conhecimentos situados e implicados com os modos de ser, estar e agir no mundo.

\section{REFERÊNCIAS}

ALHEIT, Peter ; DAUSEIN, Betina. Processus de formation et apprentissage tout au long de la vie. L'orientation scolaire et professionnelle, v. 34, n. 1, 2005. Disponível em: http://journals.openedition.org/osp/563. Acesso em 28 out. 2020.

ALVES, Camila Aloisio. L'approche biographique et la temporalité des soins palliatifs aux enfants malades chroniques : des apprentissages qui se tissent entre la vie et la mort.

Cadernos de Pesquisa, São Luis, PPPGI/UFMA, v. 27, n. 1, p. 381-399 Disponível em: http://www.periodicoseletronicos.ufma.br/index.php/cadernosdepesquisa Acesso em 10 nov. 2020.

ALVES, Camila Aloisio; DIZERBO, Anne. Le vécu de la maladie chronique et l'approche biographique dans la société contemporaine : quels enjeux éducatifs, sociaux et politiques sont en jeu ? In : Approches « (auto)biographiques et nouvelles épreuves de transitions construire du sens avec des parcours de vie ». Orgs. : Slowik, A. Rywalski, P. Souza, E. C. Paris : L'Harmattan, p. 147-158, 2019. 
ALVES, Camila Aloisio; DIZERBO, Anne. A experiência da doença crônica e a abordagem biográfica: contribuições metodológicas para a construção de um saber compartilhado. In: Ciências da saúde [recurso eletrônico] : teoria e intervenção 2 / Organizadora Marileila Marques Toledo. - Ponta Grossa, PR: Atena. https://doi.org/10.22533/at.ed.0702023041 Acesso em 10 nov. 2020.

BARBIER, Jean-Marie Barbier ; THIEVENAZ, Joris. Le travail de l'expérience, Paris : L'Harmattan, 2013, 319 p.

BRETON, Hervé. Investigação narrativa: entre detalhes e duração. REPI - Revista Educação, Pesquisa e Inclusão, Boa Vista, v. 1, n. 1 (especial), p. 12-22, 2020. Disponível em: https://revista.ufrr.br/repi/article/view/e20201 Acesso em 10 nov. 2020

CAVACO, Carmen. Experiência e formação experiencial: a especificidade dos adquiridos experienciais. Educação Unisinos, São Leopoldo, v. 13, n. 3, 220-227, 2009. Disponível em: http://revistas.unisinos.br/index.php/educacao/article/view/4949 Acesso em 10 nov. 2020

CLANDININ D. Jean; LESSARD Sean e CAINE, Vera. Reverberations of narrative inquiry. How resonant échoes of an inquiry with early school leavers shaped further inquiries. Educação Sociedade \& Culturas, Porto/Portugal n. 36, p. 7-24, 2012. Disponível em: https://www.fpce.up.pt/ciie/?q=publication/revista-educa\%C3\%A7\%C3\%A3o-sociedadeculturas/edition/educa\%C3\%A7\%C3\%A3o-sociedade-culturas-36 Acesso em 10 nov. 2020

DELORY-MOMBERGER, Christine. Trajectoires, parcours de vie et apprentissage biographique. In: DELORY-MOMBERGER C. ; SOUZA, E. C. La condition biographique. Essais sur le récit de soi dans la modernité avancée. Paris : Téraèdre, col.Autobiographie et éducation, 2009, p. 17-30.

DELORY-MOMBERGER, Christine. Fundamentos epistemológicos da pesquisa biográfica em educação. Educação em Revista, Belo Horizonte, v.27, n.01, p.333-346, $2011 \mathrm{a}$. Disponível em: http://www.scielo.br/scielo.php?script=sci_arttext\&pid=S0102$46982011000100015 \& \operatorname{lng}=$ pt\&nrm=iso Acesso em 10 nov. 2020.

DELORY-MOMBERGER, Christine. Narrativa de vida: origens religiosas, históricas e antropológicas. Revista Educação em Questão, Natal, v. 40, n. 26, p. 31-47, 2011 b. Disponível em: https://periodicos.ufrn.br/educacaoemquestao/article/view/4039 Acesso em 10 nov. 2020.

DELORY-MOMBERGER, Christine. Abordagens metodológicas na pesquisa biográfica. Revista Brasileira de Educação, v. 17, n. 51, p. 523-536, 2012. Disponível em: https://www.revistas.uneb.br/index.php/rbpab/article/view/2526 Acesso em 10 nov. 2020.

DELORY-MOMBERGER, Christine. De la recherche biographique en éducation.

Fondements Méthodes Pratiques. Paris: Téraèdre, col. Autobiographie et éducation, 2014.

DELORY-MOMBERGER, Christine. A pesquisa biográfica ou a construção compartilhada de um saber do singular. Revista Brasileira de Pesquisa (Auto) Biográfica, Salvador, v. 01, n. 01, p. 133-147, 2016. Disponível em: https://www.revistas.uneb.br/index.php/rbpab/article/view/2526 Acesso em 10 nov. 2020. 
DOMINICÉ, Pierre. La formation biographique. Paris: L’Harmattan, 2007.

HENRIQUES Fernanda. A racionalidade hermenêutica de Paul Ricoeur: diálogo, abertura e inclusão. Revista Portuguesa de História do Livro, Lisboa/ Portugal, vs. 33-34, p. 81-98, 2014. Disponível em: http://hdl.handle.net/10174/12950 Acessado em 10 nov. 2020.

JANNER RAIMONDI, Martine. Visages de l'empathie. Paris : Champ Social, 2017.

JANNER RAIMONDI, Martine. Identité narrative. In : DELORY-MOMBERGER C. (dir.) Vocabulaire des histoires de vie et de la recherche biographique. Paris : ERES, 2019, p. 94-96.

JOBERT, Guy. La place de l'expérience dans les entreprises. In: B. COURTOIS; G. PINEAU, La formation expérientielle des adultes. Paris, La Documentation Française, 1991, p.75-81.

JOSSO, Marie-Christine. O caminhar para si: uma perspectiva de formação de adultos e de professores. Entrevistador: Margaréte May Berkenbrock-Rosito Revista @mbienteeducação, São Paulo, v. 2, n.2, p. 136-139, 2009. Disponível em:

http://publicacoes.unicid.edu.br/index.php/ambienteeducacao/article/view/560/528 Acesso em 10 nov. 2020.

JOSSO, Marie-Christine. A transformação de si a partir da narração de histórias de vida. Educação, Porto Alegre, v. 3, n. 63, p. 413-438, 2007. Disponível em:

https://revistaseletronicas.pucrs.br/ojs/index.php/faced/article/view/2741 Acesso em 10 nov. 2020.

MICHEL, Johann. Narrativité, narration, narratologie : du concept ricœurien d'identité narrative aux sciences sociales. Revue européenne des sciences sociales, [En ligne], XLI125, 2003. Disponível em : http://journals.openedition.org/ress/562 ; DOI : 10.4000/ress.562 Acesso em 10 nov. 2020.

PASSEGGI, Maria da Conceição. Nada para a criança, sem a criança: o reconhecimento de sua palavra para a pesquisa (auto)biográfica. In: MIGNOT, A. C., SAMPAIO, C. S., \& PASSEGGI, M. C. (orgs.) Infância, aprendizagem e exercício da escrita. Curitiba, PR:CRV, 2014, p. 133-148.

PASSEGGI, Maria da Conceição; NASCIMENTO, Gilcilene; OLIVEIRA, Roberta Antunes. As narrativas autobiográficas como fonte e método de pesquisa qualitativa em Educação.

Revista Lusófona de Educação, Lisboa/Portugal, n. 33, pp. 111-125, 2016. Disponível em https://www.redalyc.org/articulo.oa?id=34949131009 Acesso em 10 nov. 2020.

PAUL, Patrick. Formação do sujeito e transdisciplinaridade. São Paulo: Editora Triom, 2009.

PINEAU, Gaston; Legrand, J.-L. Les histoires de vie. Collection Que sais-je ? Paris: Puf, 1993. 
PINEAU, Gaston; MARIE-MICHELE Produire sa vie : autoformation et autobiographie, Montreal : Éditions Saint-Martin ; Paris : Edilig, 2012.

PORTER, Elias. An introduction of Therapeutic Counseling, Boston, Houghton Mifflin, 1950.

RICEEUR, Paul. Existence et herméneutique. Dialogue. v. 4, p. 1-25, 1965. Disponível em: http://journals.cambridge.org/ abstract_S0012217300033278. Acesso em 05 nov. 2020.

RICEEUR, Paul. Temps et récit I, Coll. L'ordre philosophique. Paris, Seuil, 1983.

RICCEUR, Paul. Temps et récit III. Paris : Seuil, 1985

ROGERS, Carl. Le développement de la personne. Paris: Dunod, 1967.

SOUZA, Elizeu Clementino. (Auto)biografia, histórias de vida e práticas de formação. In NASCIMENTO, AD., HETKOWSKI, TM., orgs. Memória e formação de professores [online]. Salvador: EDUFBA, 2007. Pp. 59-74. Disponível em: http://books.scielo.org. Acesso em 10 nov. 2020

STRAUBER, Barbara. Taking the Biographical Approach Seriously - What Does it Mean for the Concept of Biographicity? Revista de Sociología de la Educación (RASE), Valência/Espanha, v. 11, n.2, p. 216-227, 2018. Disponível em: https://ojs.uv.es/index.php/RASE/article/view/12305 Acesso em 10 nov. 2020.

\section{SOBRE A AUTORA:}

\section{Camila Aloisio Alves}

Doutora em ciências da saúde pelo Instituto Nacional de Saúde da Mulher, Criança e Adolescente Fernandes Figueira (IFF/FIOCURZ). Professora da Faculdade de Medicina de Petrópolis (FMP) e pesquisadora associada da Université Sorbonne Paris Nord, Centre de Recherche Experice. E-mail: camila.aloisioalves@gmail.com

(iD https://orcid.org/0000-0002-3477-0367 